\title{
Validation of the Goal Content for Exercise Questionnaire (GCEQ) for a sample of elderly Portuguese people
}

\author{
Raul Antunes ${ }^{1 *}$, Nuno Couto1, Diogo Monteiro1,3, João Moutão1,3, Daniel A. Marinho ${ }^{2,3}$, Luis \\ $\mathrm{Cid}^{1,3}$
}

\begin{abstract}
According Sebire, Standage and Vansteenkiste (2008), goals contents (motives) are the major drivers of behavior, giving rise to the goal content theory, which is in the basis of Goal Content for Exercise Questionnaire (GCEQ: Sebire et al., 2008) development. So, the main goal of present study was to conduct the validation of GCEQ for a sample of Portuguese elderly $(\mathrm{n}=311)$, with equal or higher ages than 60 years old $(M=68.53$; $D P=6.69)$. The main results show us that CGEQ measurement model ( 5 factors, 20 items) only present adequate fit to data after the elimination of 3 items: $S-B \chi^{2}=219.9, \mathrm{df}=109, \mathrm{p}=.001$, $\mathrm{SRMR}=.049, \mathrm{TLI}=.916, \mathrm{CFI}=.934$, RMSEA $=.057, \mathrm{RMSEA} 90 \% \mathrm{CI}=.046-.068, \mathrm{PCFI}=.747)$. Besides that, the 5 factors show us acceptable values of composite reliability: between .76 and .88. Those findings allow us to conclude that GCEQ with 5 factors and 17 items can be used to measure goal content in a population of elderly Portuguese people in physical activity domain.

Keywords: Goal Content, exercise, elderly people, confirmatory factorial analysis.
\end{abstract}

\section{INTRODUCTION}

Understanding the underlying reasons behind human involvement in a certain activity is one of the major questions in social science investigations, and motivation has clearly been one of the most studied themes in several fields, notably, in sports sciences (Biddle \& Mutrie, 2007).

Motivation has a crucial role in every aspect of life; it is an authentic "engine" for executing any sort of activity and it can be defined as a psychological variable that drives an individual towards the action, orientation, maintenance, or dropout of a sport or physical activity (Dosil, 2008). Motivation can be determined by the cognitive association of distinct situations, due to a set of both environmental and individual factors, resulting from the interaction, between these situations and the motivation to perform a certain activity (Samulski, 2002). Therefore, motivation concerns the behavioural aspects of activation and intention, namely energy, direction, persistence and equifinality (Ryan \& Deci, 2000).

Among the several theoretical models that approach motivation, Self Determination Theory (SDT: Deci \& Ryan, 1985) is one of the most important, since represents a macro theory regarding human motivation (Deci \& Ryan, 2008) that is concerned with the causes and consequences of the intrinsically motivated behaviour. According to the authors, this theory implies that the subjects' motivation is mediated by the satisfaction of three basic psychological needs (autonomy: ability to regulate one's own actions; competence: efficacy ability to interact with the involvement; relatedness: ability to search for and develop connections and interpersonal relationships) (Ryan \& Deci, 2007). These three basic psychological needs will determine the individual's regulation of behaviour by a motivational continuum that oscillates between more autonomous or more controlled forms of behaviour regulation (Deci \& Ryan, 1985; Ryan \& Deci, 2002): amotivation

\footnotetext{
Manuscript received at July 17 ${ }^{\text {th }} 2016$; Accepted at January $1^{\text {st }} 2017$

1. Escola Superior de Desporto de Rio Maior, ESDRM-IPSANTARÉM, Rio Maior, Portugal

2. Universidade da Beira-Interior, UBI, Covilhã, Portugal

3. Research Center in Sport, Health and Human Development, CIDESD

* Corresponding author: Escola Superior de Desporto de Rio Maior, ESDRM-IPSANTARÉM), Av. Dr. Mário Soares, n. ${ }^{\circ} 110,2040-413$, Rio Maior E-mail: rantunes@esdrm.ipsantarem.pt.
} 
(absence of regulation or lack of intention to act); external motivation (the behaviour is accomplished to satisfy external demands, meaning, to obtain rewards or avoid punishment); introjected motivation (the behaviour is executed to avoid negative feelings such as guilt and/or anxiety); identified motivation (the behaviour is personally accepted as important since the individual identifies himself with the objective/value); integrated motivation (the individual internalises the behaviour as part of himself); intrinsic motivation (the behaviour is accomplished for its intrinsic pleasure, interest, amusement, and satisfaction).

In brief, according to Deci and Ryan (2008), the main central difference within the selfdetermination theory is between autonomous motivation (intrinsic motivation, integrated and identified extrinsic motivation) and controlled motivation (introjected and external extrinsic motivation).

According to Ryan and Deci (2007), intrinsic motivation is among the major factors in the maintenance of a behaviour related to physical activity, since those people who regulate their motivation in this fashion show greater persistence, commitment, and pleasure in their activities (Deci \& Ryan, 2000) and involvement in a behaviour for intrinsic goals is a potential generator of wellbeing (Teixeira, Carraça, Markland, Silva, \& Ryan, 2012). In this sense, Sebire, Standage and Vansteenkiste (2008) suggested that it is the goal content (motives) that is the major impetus for the individuals' behaviour.

The goal content theory makes a distinction between intrinsic and extrinsic goals, as well as analysing its impact on motivation regulation and wellbeing (Sebire et al., 2008). According to the authors, the goals are then viewed according to the way they can provide satisfaction of the three basic psychological needs (autonomy, competence, and relatedness) and they have a differentiated impact on the individuals' wellbeing, taking into consideration their content (intrinsic or extrinsic). In other words, the basic psychological needs are satisfied in a differentiated way, as a function of the goals content that people show (expectation of what they hope to accomplish). For instance, goals such as self-acceptance, affiliation, community contribution or even health can be seen as a chance to satisfy the basic psychological needs, and, thus, are labelled as intrinsic goals. On the other hand, goals such as searching for fame, physical appearance, and economic success seem not to satisfy the basic psychological needs, and, thus, are labelled as extrinsic goals.

Therefore, although there were instruments that assess the motives (goal content) for the practice of physical activity, the Goal Content for Exercise Questionnaire (GCEQ: Sebire et al., 2008) was developed based on the conceptual framework of SDT. The CGEQ aims to assess the importance that people place on their efforts and on the practice of physical activity. Their 5 factors, based on the SDT inputs and on the motives specification (Goal Content) within the physical exercise context, are: social affiliation (the goal to create significant and close bonds with other individuals); image (the goal to improve image and physical appearance); health management (the goal to improve health and physical performance); social recognition (the goal to be admired and recognised by others in the exercise context); skills development (the goal to acquire and develop skills).

The study of Sebire et al., (2008), which was developed and validated with a sample of 312 individuals, with ages ranging from 19 to 63 years old $(\mathrm{M}=34.44 ; \mathrm{SD}=11.88)$, resorts to $\mathrm{a}$ confirmatory factorial analysis, of which the initial model (5 factors, 26 items) shows a good adjustment to the data. However, to improve the model, the authors decided to eliminate also the items that showed cross-loadings and being associated with multiple measurements errors. Therefore, to guarantee the parity of the number of items of each factor, the final model result in a structure of 5 factors and 20 items that, according to the authors, adjusted excellently to the data $\left(\chi^{2}\right.$ $=301.14 ; \mathrm{df}=160 ;$ CFI $=.97$; SRMR $=.05$; RMSEA $=.05$; RMSEA 90\%CI $=.04-.06)$. In the same study, a second order model with two factors was tested: intrinsic goals (health management, skills development and social affiliation) and two extrinsic factors (image and social recognition), that show similar results to 
the first order model $\left(\chi^{2}=355.30 ; \mathrm{df}=164\right.$; CFI $=.95 ;$ SRMR $=.07 ;$ RMSEA $=.06$; RMSEA $90 \% \mathrm{CI}=.05-.07)$.

The CGEQ has been used in several studies in last years, for example, Sebire, Standage, and Vansteenkiste (2009) in a study conducted with 410 adults $(M=41.39$ e $S D=11.02)$, concluded that the content of most intrinsic goals positively predicted cognitive, affective and behavioural adaptation to exercise, and also identified the effects of most intrinsic goals on physical selfesteem and on psychological well-being. In another study, Sebire, Standage, and Vansteenkiste (2011), using a sample of 101 adults $(\mathrm{M}=38.79$ years; $\mathrm{SD}=11.5)$, analyse the predictive effect of goal content on physical activity, and the results show no correlations between intrinsic goals and physical activity behaviour, however, through an analysis of the mediating effect of autonomous motivation, they concluded that goal content may predict individuals' physical activity.

In Portugal, the GCEQ was translated and validated in a preliminarily study, conducted by Ramos, Cid and Moutão (2013), on a sample of gym exercisers $(n=389)$, with a mean age of 31.4 $(\mathrm{SD}=11.15)$ years old, the initial model (5 factors, 20 items) show some issues (e.g., crossloadings) in the adjustment to data that leads to a final model of 5 factors and 15 items with acceptable fit: $\chi^{2}=299.09 ; \mathrm{p}=.00 ; \chi^{2} / \mathrm{df}=3.74$; SRMR $=.06 ; \mathrm{NNFI}=.88 ; \mathrm{CFI}=.91 ; \mathrm{RMSEA}=$ .08 ; RMSEA $90 \% \mathrm{CI}=.07-.09$.

Therefore, since that there are no validation studies of this instrument with elderly subjects, our main purpose was to analyse the psychometric properties of the GCEQ measurement model in a sample of elderly individuals (60 years or older).

\section{Participants}

The sample was comprised of, 311 individuals $(\mathrm{n}=311), 244$ females and 67 males, who were aged between 60 to 90 years $(\mathrm{M}=68.63$; $\mathrm{DP}=$ 6.55), all being attendees of Senior Universities and day care centres in the Ribatejo and West zone regions of continental Portugal. From the total sample, $79.7 \%$ were found to practice physical activity regularly with a frequency of 1 to 7 times per week $(M=1.73$; $\mathrm{DP}=1.53)$, with duration sessions ranging from 30 to 120 minutes. Subjects also reported an PA-related experience that ranged from 1 to 564 months (M $=51.95, \mathrm{SD}=76.9)$. Among the related activities, the most common were: maintenance gymnastics, aerobics, water aerobics.

The present study takes part of a research project approved by the Regional Health Administration of Lisboa e Vale do Tejo (ARSLVT) Ethics Committee, under the registration reference 128 / CES / INV / 2013.

\section{Instruments}

The Goal Content for Exercise Questionnaire (GCEQ: Sebire et al., 2008) consists of 20 items, which are answered on a Likert type scale, with 7 response options, that vary from 1 ("totally disagree") to 7 ("fully agree"). Later the items are grouped in five factors: health management (e.g., "to improve my overall health"; skills development (e.g., "to acquire new exercise skills"; social affiliation (e.g., "to develop close friendships"; image (e.g., "to improve my appearance"; social recognition (e.g., "to be socially respected by others"), each one having four items. In this study, the preliminary translated and validated version of Ramos et al. was used (2013).

\section{Procedures \\ Data collection procedures}

After being contacted in senior universities and day care centres, and the signing of informed consent by the participants, all the data were collected and analysed anonymously guaranteeing the principle of confidentiality. It should be pointed out that the data were collected in a classroom context in the senior universities, by small groups (maximum of 20 individuals), taking on average 20 minutes for their contribution. Every subject answered autonomously, thereby there was no need to differentiate the application of the instrument. 


\section{Data analysis}

In relation to the data analysis, it was taken into consideration the recommendations suggested by Byrne (2001; 2006), Hair, Black, Babin and Anderson (2014), Kahn (2006), Worthington and Whittaker (2006). Therefore, the confirmatory factor analysis was operationalized using maximum likelihood (ML).

The following goodness-of-fit-indexes of adjustment quality were used: Standardized Root Mean Square Residual (SRMR), Comparative Fit Index (CFI), Tucker-Lewis Index (TLI), Root Mean Square Error of Approximation (RMSEA) and the respective confidence interval $(90 \% \mathrm{CI})$. In the present study, the cut-off values suggested by $\mathrm{Hu}$ and Bentler (1999) were adopted: SRMR $\leq$ 0.08 , CFI e TLI $\geq 0.95$ e RMSEA $\leq$ 0.06., although on the incremental indexes (CFI and TLI) the cut-off values of $\mathrm{Hu}$ and Bentler (1999) should not be generalised, it being equally advisable to consider values equal or above to .90 (Marsh, Hau, \& Wen, 2004). We also analysed the parsimony indexes (e.g., parsimony comparative fit index - PCFI), especially used when the models are non-nested. According to Mâroco (2010) and Hair et al. (2014), cut-off values between .60 and .80 must be considered as good model adjustment, and values higher than .80 are representative of an excellent adjustment.

Besides analysis of normal univariate distribution through standardized value ( $\mathrm{Z}$ value) of the skewness and kurtosis, the underlying theory of the estimation method ML (maximum likelihood) assumes that the data has a normal multivariate distribution (Kahn, 2006; Kline, 2005), this being necessary to analyse the coefficient of Mardia (see Mardia, 1970) and check the normality of the data (Hoyle \& Panter, 1995). According to Byrne (2006), if the normalised Mardia coefficient is above 5.0 it is an indication that the data does not have a normal multivariate distribution, a situation that occurs with our sample (kurtosis multivariate: Mardia $=$ 163.68; normalised Mardia $=48.65$ ). Because of that, we used the Satorra-Bentler correction (S-
B $\chi^{2}$ : see Satorra \& Bentler, 1994), which corrects the values into the non-normality of data distribution and produces more satisfactory results (Chou \& Bentler, 1995).

Concerning the analysis of the convergent validity (with the objective of verifying if the items are related with the respective factor), a calculation was made of the average variance extracted (AVE), using the recommended reference values (AVE $\geq .50$ ) (Hair et al., 2014). Relative to the discriminant validity (to assess if the factors are sufficiently distinct from each other), it was verified if the square of the factors correlation is below the AVE of the same (Hair et al., 2014). The Cronbach's alpha $(\alpha)$ and composite reliability (CR) were calculated, to evaluate the internal consistency of the factors, adopting as cut-off values .70 as suggested by Nunnaly (1978) and Hair et al. (2014), respectively.

\section{RESULTS}

As we can see in table 1, we can verify that the subjects used all levels of answer (e.g., between 1 and 7) the higher average being verified on the items related to the "health motives" factor (e.g., item 3 "to increase my resistance towards illness" and factor 13 "to improve my overall health", whereas the lower mean values are verified on the "social recognition" factor (e.g., item 14 "to be accepted by others" and item 19 "so that others recognise me as a sportsman"). These mean values are, in a certain way, confirmed by the univariate non-normal distribution, which show a tendency to skew to the left, centred on the right side of the scale, which means, on the answers "agree", "quite agree" and "fully agree", asymmetrical results can be seen.

Regarding the adjustment of measurement model to the data, as can be seen on Table 2, the initial model (e.g., 5 factors/20 items) did not adjust satisfactorily to the data (see model 1, table 2), as the cut-off values adopted ( $\mathrm{Hu} \&$ Bentler, 1999) were not reached. 
Table 1

Descriptive Analysis of the answers to the items of the Goal Content for Exercise Questionnaire (GCEQ)

\begin{tabular}{lcccccc}
\hline \multicolumn{1}{c}{ Item } & Min-Max & $\mathrm{M} \pm \mathrm{SD}$ & Skewness & Value Z & Kurtosis & Value Z \\
\hline Item 1 (SA) & $1-7$ & $5.10 \pm 1.55$ & -0.93 & -6.74 & 0.74 & 2.69 \\
Item 2 (I) & $1-7$ & $5.21 \pm 1.33$ & -0.98 & -7.10 & 1.66 & 6.02 \\
Item 3 (HM) & $1-7$ & $6.04 \pm 0.95$ & -0.90 & -6.52 & 1.66 & 6.02 \\
Item 4 (SR) & $1-7$ & $4.02 \pm 1.59$ & -0.12 & -0.87 & -0.31 & -1.12 \\
Item 5 (SD) & $1-7$ & $5.13 \pm 1.31$ & -0.75 & -5.43 & 1.28 & 4.64 \\
Item 6 (AS) & $1-7$ & $4.89 \pm 1.40$ & -0.68 & -4.93 & 0.61 & 2.21 \\
Item 7 (I) & $1-7$ & $5.11 \pm 1.28$ & -0.95 & -6.88 & 1.91 & 6.93 \\
Item 8 (HM) & $1-7$ & $5.88 \pm 0.95$ & -0.31 & -2.25 & -0.65 & -2.36 \\
Item 9 (SR) & $1-7$ & $4.12 \pm 1.74$ & -0.15 & -1.09 & -0.64 & -2.32 \\
Item 10 (SD) & $1-7$ & $5.14 \pm 1.36$ & -0.87 & -6.30 & 1.11 & 4.03 \\
Item 11 (SA) & $1-7$ & $5.10 \pm 1.38$ & -1.04 & -7.54 & 1.57 & 5.70 \\
Item 12 (I) & $1-7$ & $3.90 \pm 1.61$ & -0.21 & -1.52 & -0.47 & -1.71 \\
Item13 (HM) & $1-7$ & $6.31 \pm 0.91$ & -1.60 & -11.59 & 4.16 & 15.09 \\
Item 14 (SR) & $1-7$ & $3.70 \pm 1.57$ & -0.06 & -0.43 & -0.28 & -1.02 \\
Item 15 (SD) & $1-7$ & $4.63 \pm 1.51$ & -0.73 & -5.29 & 0.38 & 1.38 \\
Item 16 (SA) & $1-7$ & $4.73 \pm 1.38$ & -0.87 & -6.30 & 1.27 & 4.61 \\
Item 17 (I) & $1-7$ & $4.38 \pm 1.51$ & -0.51 & -3.70 & 0.14 & 0.51 \\
Item 18 (HM) & $1-7$ & $5.87 \pm 1.05$ & -1.02 & -7.39 & 2.29 & 8.31 \\
Item 19 (SR) & $1-7$ & $3.32 \pm 1.56$ & 0.12 & 0.87 & -0.41 & -1.49 \\
Item 20 (SD) & $1-7$ & $4.97 \pm 1.45$ & -0.84 & -6.09 & 1.00 & 3.63 \\
\hline N & $1-7$ &
\end{tabular}

Note. SA (Social Affiliation); I (Image); HM (Health Management); SR (Social Recognition); SD (Skills Development); $M=$ Mean; $\mathrm{SD}=$ Standard Deviation; Min= Minimum value; $\mathrm{Max}=$ Maximum value

Therefore, we looked into potential fragilities within the model, through the analysis of the residual values between the items and the modification indexes, and hence the model was readjusted by the elimination of items 1, 12 and 15 since there were observable residual values much higher than the other items and because the Lagrange Multiplier test and the Wald Test suggest the possibility of a strong relation existing (e.g., cross-loading) with other factors. After this change, (see model 2 from table 2 ), we can verify that the model adjusted satisfactorily to the data $\left(\mathrm{S}-\mathrm{B} \chi^{2}=\right.$ 219.9; $\mathrm{df}=109 ; \mathrm{p}=.001 ; \mathrm{TLI}=.916 ; \mathrm{CFI}=.934$; SRMR $=.049 ;$ RMSEA $=.057$; RMSEA IC 90\% $=.046-$ .068 ; PCFI $=.747)$, although the cut-off values of $\mathrm{Hu}$ and Bentler (1999) were not achieved, not all the authors advise generalising for these values; .90 is considered a satisfactorily cut-off value for the incremental indexes (Marsh, Hau, \& Wen, 2004), and .08 for the RMSEA (Hair et al., 2014).

The model of 15 items/5 factors (see model 3, table 2), preliminarily validated by Ramos, Cid and Moutão (2013) was also analysed in our sample, and the results revealed that this model can also adjust to the data satisfactorily $\left(\mathrm{S}-\mathrm{B} \chi^{2}=164.01 ; \mathrm{df}=80 ; \mathrm{p}=.001\right.$; TLI $=.916 ; \mathrm{CF} \mathrm{I}=.936 ; \mathrm{SRMR}=.049 ; \mathrm{RMSEA}=.058$; RMSEA IC $90 \%=.045-.071$; PCFI $=.713$ ), thus it can be configured as an alternative to model 2 .

Table 2

Adjustment index of the tested models

\begin{tabular}{cccccccccc}
\hline Models & $\mathrm{S}-\mathrm{B} \chi^{2}$ & $d f$ & $p$ & SRMR & TLI & CFI & RMSEA & $90 \%$ CI & PCFI \\
\hline Model 1 & 381.1 & 160 & $.001^{*}$ & .063 & .71 & .895 & .067 & $.058-.075$ & .750 \\
Model 2 & 219.9 & 109 & $.001^{*}$ & .049 & .916 & .934 & .057 & $.046-.068$ & .747 \\
Model 3 & 164.0 & 80 & $.001^{*}$ & .049 & .916 & .936 & .058 & $.045-.071$ & .713 \\
Model 4 & 286.1 & 113 & $.001^{*}$ & .077 & .874 & .895 & .070 & $.060-.080$ & .743 \\
\hline
\end{tabular}

Note. S-B- $\chi^{2}=$ chi-square with a Satorra-Bentler correction; $\mathrm{df}=$ degrees of freedom; SRMR $=$ Standardised Root Mean Square Residual; TLI = Tucker-Lewis Index; CFI = Comparative Fit Index; RMSEA = Root Mean Squared Error of Approximation; $90 \%$ $\mathrm{CI}=$ confidence interval of the RMSEA value; PCFI= Parsimony CFI; Model 1 (20 items); Model 2 (17 items); Model 3 (15 items presented by Ramos, et al., 2013); Model 4 (two $2^{\text {nd }}$ order factors - intrinsic motives and extrinsic motives).

Just like the authors' study of the original instrument (Sebire, Standage, \& Vansteekiste, 2008), starting from the model 2 (5 factors, 17 items) we tested a second order model with two factors: intrinsic goals (health management, skills, development of social affiliation) and two extrinsic factors (appearance and social recognition). As we can verify, this model (see model 4, table 2), shows no adjustment to the data $\left(\mathrm{S}-\mathrm{B} \chi^{2}=286.1 ; \mathrm{df}=113 ; \mathrm{p}=.001 ; \mathrm{TLI}=.874 ; \mathrm{CFI}=\right.$ .895 ; SRMR $=.077$; RMSEA $=.070$; RMSEA IC $90 \%$ $=.060-.080 ;$ PCFI $=.743$ ). 


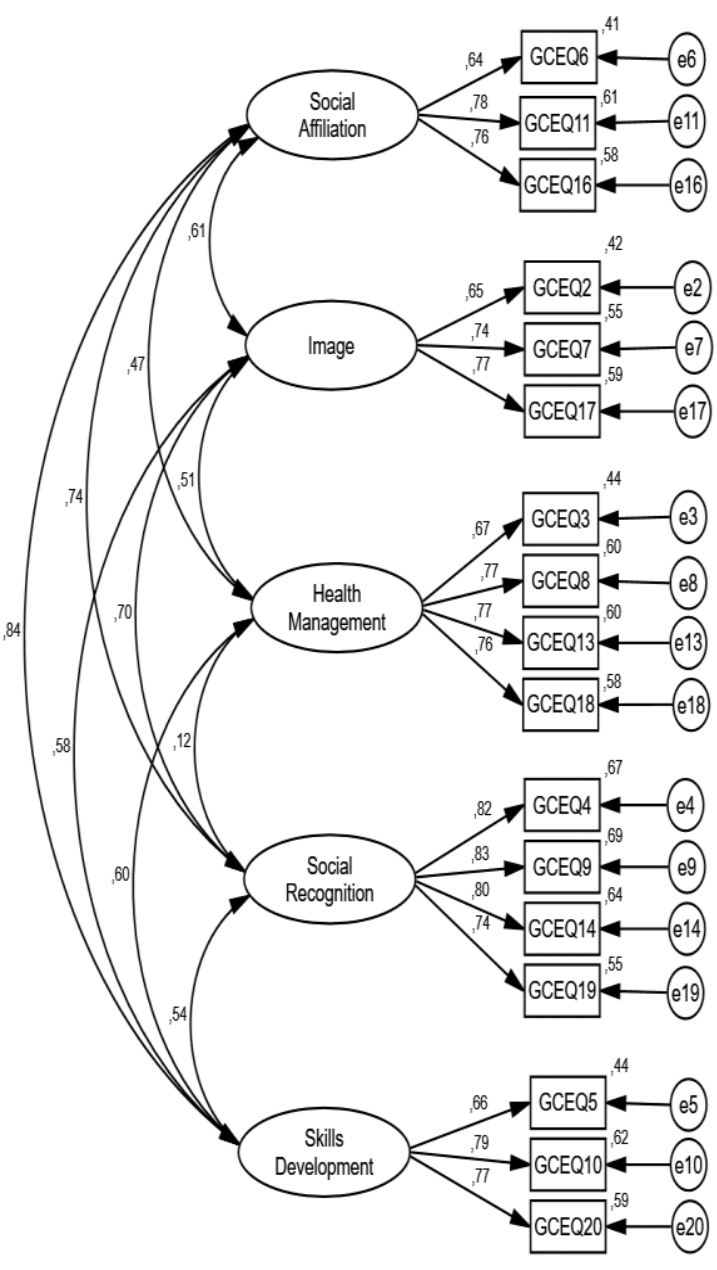

Figure 1. Standardized individual parameters of the Portuguese version of the Goal Content for Exercise Questionnaire (GCEQ-P)-model 2 (17 items/5 factors)

Table 3

Composite Reliability, discriminant and convergent validity and Cronbach's alpha on the diagonal.

\begin{tabular}{lccccccc}
\hline \multicolumn{1}{c}{ Factors } & CR & AVE & 1 & 2 & 3 & 4 & 5 \\
\hline 1.Social Affiliation & .77 & .53 & $\alpha=.76$ & & & & \\
2.Image & .76 & .57 & $.37^{*}$ & $\alpha=.76$ & & & \\
3.Health Management & .83 & .55 & $.22^{*}$ & $.26^{*}$ & $\alpha=.83$ & & \\
4.Social Recognition & .78 & .64 & $.55^{*}$ & $.49^{*}$ & $.01^{*}$ & $\alpha=.87$ & \\
5.Skills Development & .88 & .55 & $.71^{*}$ & $.34^{*}$ & $.36^{*}$ & $.29^{*}$ & $\alpha=.78$
\end{tabular}

Taking into consideration the adjustment results of the individual parameters from the model, and as can be verified in figure 1 , the factor loadings varying from .64 (item 6 "to share my practice experiences (exercise) with people that care about me" and .83 (item 9 "to be socially respected by others"). Regarding the relation between the variables, the values show a significant positive correlation between all the factors with the exception of the relation between social recognition and health management, which, in spite of being positive, is not significant $(\mathrm{r}=.12, \mathrm{p}=.076)$.

In relation to the internal reliability of the factors, we can verify that the Cronbach's alpha shows values of internal consistency that we can consider acceptable in all the factors $\left(\alpha_{\text {social affiliation }}\right.$ $=.76 ; \alpha$ image $=.76 ; \alpha$ health management $=.83 ; \alpha$ social recognition $\left.=.87 ; \alpha_{\text {skills development }}=.78\right)$. Besides that, it was also verifiable that none of the items increased their internal consistency from the respective factor as a result of being eliminated.

Furthermore, in Table 3, we can verify that the measurement model shows good values of composite reliability (> .70), such as recommended by Hair et al. (2014). Regarding convergent validity, the results indicate that all the factors show higher values than the recommended cut-off values (AVE $\geq .50$ ) (Hair et al., 2014). On the other hand, concerning the discriminant validity, issues are only verifiable between the social affiliation factor and the skills development factor $\left(r^{2}=.67\right)$, since on every other factor the square of the correlations is below the AVE of the same (Hair et al., 2014).

Note. Composite Reliability (CR); Average Variance Extracted (AVE); *Square Correlation (r2)

\section{DISCUSSION}

Taking into consideration the main purpose of this study consisted in validating a Portuguese version of the Goal Content for Exercise Questionnaire (GCEQ: Sebire et al., 2008) to a sample of Portuguese elderly people, with a group aged 60 and above, we verified that the initial model (e.g., 5 factors $/ 20$ items) did not adjust satisfactorily to the data. However, as mentioned before, we proceeded to the adjustment of the model by eliminating items 1 , 12 and 15 (factors of social affiliation, image, 
skills development, respectively), resulting in a model of 5 factors and 17 items that show adjustment values significantly better than the previous model and achieve recommended cutoff values less conservative of Marsh el al (2004). The eliminated items show associations with other factors (e.g., item 15 of the skills development factor "to become competent in a certain exercise or activity" associates with the social recognition factor, specially by the association with item 14 "to be accepted by others") which assumes that the subjects might be interpreting differently from what is supposed.

This situation can be justified by semantical point of view, since the subjects can be involved in exercise to develop skills and they expect to be accepted by others. On other hand, there is also an empirical justification, since results revealed a positive correlation $(\mathrm{r}=.54)$ between two factors: "skills development" and "social recognition"). However, from a conceptual point of view, taking into consideration the theoretical framework (Sebire et al., 2008), a correlation of this nature should not have been verified, since "skills development" factor is associated with intrinsic motives, and "social recognition" factor is associated with extrinsic motives. A similar situation happened with items 1 (social affiliation) and 12 (image), that are associated with appearance and health factors. In our opinion, these results may indicate that motives related with physical appearance may be interpreted as a promoter of goals related with social affiliation $(\mathrm{r}=.61)$ and health management $(\mathrm{r}=.51)$ in elderly population. The same evidence was found also in a Ramos et al. (2013) study, in fitness domain, where the image showed also significant positive correlations with the factors mentioned, especially with health management $(\mathrm{r}=.61)$.

However, although the adjustment levels of the model (e.g., 5 factors/ 17 items) did not reach the more conservative cut-off values of $\mathrm{Hu}$ and Bentler (1999), adopted in the methodology, we consider the model acceptable, as there are authors (e.g., Marsh et al., 2004) that consider that the cut-off values of $\mathrm{Hu}$ and Bentler (1999) should not be generalised, otherwise good models would be rejected; the vast majority of authors recommend less conservative cut-off values (e.g., CFI e TLI $\geq .90$ e RMSEA $\leq .08$ ) (Hair et al., 2014, Marsh et al., 2004).

Finally, as the authors of the original instrument (Sebire et al., 2008), we also tested a second order model ( 2 factors of $2^{\text {nd }}$ order, 5 factors of $1^{\text {st }}$ order, 17 items): intrinsic motives (health management, skills development, social affiliation) and extrinsic motives (image, social recognition), which did not show satisfactory adjustment values (see table 2). However, Sebire et al. (2008) supported a five factor factorial solution, with factors tapping intrinsic (social affiliation, health management, and skill development) and extrinsic (social recognition and image) goals.

Although theoretically distinct constructs, intrinsic and extrinsic goals display a tendency to be pursued for autonomous and controlled regulations, respectively (Sheldon, Ryan, Deci, \& Kasser, 2004), and the study conducted by Sebire et al. (2008) put these in evidence because intrinsic and extrinsic goal show a tendency to correlate more strongly with autonomous and controlled exercise regulations, respectively.

Therefore, concerning the values of internal consistency (Cronbach's alpha and composite reliability), and the recommendation of Hair et al. (2014), it is suggested that items of all factors are assessed identically and simultaneously their respective constructs. Regarding the convergent validity, the results show that the items are strongly associated to respective factor, since all the values are above the recommended (AVE $\geq .50$ ) (Hair et al., 2014). Relative to discriminant validity, the results indicate that the constructs are sufficiently independent from each other, with the exception of the social affiliation and skills development pair $\left(r^{2}=.67\right)$, since in every other factor the square of the correlations factors is below the AVE of the same (Hair et al., 2014). On other hand, the value of discriminant validity shown by the referred pair of factors (e.g., social affiliation and development of skill) can be explained by literature, which considers them to be relative factors to intrinsic motives (Sebire et al., 2008). 


\section{CONCLUSION}

The measurement model (2 factors and 17 items) of Portuguese version of GCEQ has satisfactory psychometric properties to assess the goal content (motives) for physical activity practice in the elderly Portuguese population, maintaining the congruence relatively to original version of questionnaire (Sebire et al., 2008). However, the results did not provide satisfactory support for higher order structure of the GCEQ as the original version, which may be require more research in future. Even so, the construct captured the importance placed on exercise goals in light of the intrinsic and extrinsic goal content dichotomy highlighted in SDT (Deci \& Ryan, 2000).

Besides that, to address some of the limitations associated with a sample of the present study, we also recommend more studies about GCEQ validation, especially with younger exercisers, and also about model invariance across gender, age, and type of physical activity or exercise.

\section{Acknowledgments:}

Nothing to declare.

\section{Conflict of interests:}

Nothing to declare.

\section{Funding:}

This work was financed by National Funds through FCT - Foundation for Science and Technology within the framework of the project UID/DTP/04045/2013

\section{REFERENCES}

Biddle, S., \& Mutrie, N. (2007). Psychology of physical activity: determinants, well-being and interventions. London: Routledge, Taylor \& Francis Group.

Byrne, B. (2001). Structural equation modeling with AMOS. Basic concepts, applications and programming. Mahwah, NJ: Lawrence Erlbaum.

Byrne, B. (2006). Structural equation modeling with EQS. Basic concepts, applications, and programming (2nd ed.). Mahwah, NJ: Lawrence Erlbaum.

Chou, C., \& Bentler, P. (1995). Estimates and tests in structural equation modeling. In R. Hoyle (Ed.), Structural equation modeling. Concepts, issues, and applications (pp. 37-54). Thousand Oaks, CA: Sage.
Deci, E., \& Ryan, R. (1985). Intrinsic motivation and selfdetermination in human behavior. New York: Plenum Press.

Deci, E., \& Ryan, R. (2000). The "what" and "why" of goal pursuits: human needs and the selfdetermination of behavior. Psychological Inquiry, 11(4), 227-268. doi: 10.1207/S15327965PLI1104_01

Deci, E., \& Ryan, R. (2008). Self-determination theory: a macrotheory of human motivation, development, and health. Canadian Psychology, 49(3), 182 185. doi: 10.1037/a0012801

Dosil, J. (2008). Psicologia de la actividad física y del deporte ( $2^{\mathrm{a}}$ ed.). Madrid: McGraw Hill.

Hair, J., Black, W., Babin, B., \& Anderson, R. (2014). Multivariate data analysis (7 th ed.). Upper Saddle River, NJ: Pearson Educational.

Hoyle, R., \& Panter, A. (1995). Writing about structural equation models. In R. Hoyle (Ed.), Structural equation modeling. Concepts, issues, and applications (pp. 158-176). Thousand Oaks, CA: Sage.

Hu, L., \& Bentler, P. (1999). Cutoff criteria for fit indexes in covariance structure analysis: Conventional criteria versus new alternatives. Structural Equation Modeling, 6(1), 1-55. doi: $10.1080 / 10705519909540118$

Kahn, J. (2006). Factor analysis in counseling psychology. Research, training, and practice: Principles, advances and applications. The Counseling Psychologist, 34(5), 684-718. doi: 10.1177/0011000006286347

Kline, R. (2005). Principles and practice of structural equation modeling ( $2^{\text {nd }}$ ed.). New York: The Guilford Press.

Mardia, K. (1970). Measures of multivariate skewness and kurtosis with applications. Biometrika, 57(3), 519-530. doi: 10.2307/2334770

Maroco, J. (2010). Análise de Equações Estruturais: Fundamentos teóricos, Software e Aplicações. Pêro Pinheiro: ReportNumber.

Marsh, H., Hau, K., \& Wen, Z. (2004). In search of golden rules: Comment on hypothesis-testing approaches to setting cutoff values for fit indexes and dangers in overgeneralizing $\mathrm{Hu}$ and Bentler's (1999) findings. Structural Equation Modeling, 11(3), 320-341. doi: $10.1207 /$ s15328007sem1103_2

Nunnally J. C. (1978). Psychometric theory. NewYork, NY: McGraw-Hill Inc

Ramos, E., Cid, L., \& Moutão, J. (2013). Avaliação do conteúdo dos objetivos de prática de exercício físico: Propriedades psicométricas da versão portuguesa do Goal content for exercise questionnaire. Paper presented in III Congresso Galego-Português de Psicologia da Atividade Física e do Desporto e XIV Jornadas da Sociedade de Psicologia do Desporto. Maia: Instituto Superior da Maia (ISMAI), novembro, 2013.

Ryan, R., \& Deci, E. (2000). Self-determination theory and the facilitation of intrinsic motivation, 
social development and well-being. American Psychologist, 55(1), 68--78. doi: 10.1037/0003066X.55.1.68

Ryan, R., \& Deci, E. (2002). Overview of selfdetermination theory: an organismic dialectial perspective. In E. Deci \& R. Ryan (Eds.), Handbook of self-determination research (pp. 3-33). Rochester, New York: The University of Rochester Press.

Ryan, R., \& Deci, E. (2007). Active human nature: self-determination theory and the promotion and maintenance of sport, exercise, and health. In M. Hagger \& N. Chatzisarantis (Eds.), Intrinsic motivation and self-determination in exercise and sport (pp. 1-19). Champaing, Illinois: Human Kinetics.

Samulski, D. (2002). Psicologia do esporte. S. Paulo: Editora Manole.

Satorra, A., \& Bentler, P. (1994). Corrections to test statistics and standard errors in covariance structure analysis. In A. Eye \& C. Clogg (Eds.), Latent variables analysis: Applications for development research. Thousand Oaks, CA: Sage.

Sebire, S. J., Standage, M., \& Vansteenkiste, M. (2008). Development and validation of the goal content for exercise questionnaire. Journal of Sport $\mathcal{E}$ Exercise Psychology, 30, 353-377.
Sebire, S., Standage, M., \& Vansteenkiste, M. (2009). Examining intrinsic versus extrinsic exercise goals: Cognitive, affective, and behavioral outcomes. Journal of Sport and Exercise Psychology, 31, 189-210.

Sebire, S., Standage, M., \& Vansteenkiste, M. (2011). Predicting objectively assessed physical activity from the content and regulation of exercise goals: Evidence for a mediational model. Journal of Sport \& Exercise Psychology, 33, 175-197.

Sheldon, K., Ryan, R., Deci, E., \& Kasser, T. (2004). The independent effects of goal contents and motives on well-being: it's both what you pursue and why you pursue it. Personality and Social Psychology Bulletin, 30, 475-486. doi: 10.1177/0146167203261883

Teixeira, P., Carraça, E., Markland, D., Silva, M., \& Ryan, R. (2012). Exercise, physical activity, and self-determination theory: a systematic review. International Journal of Behavioral Nutrition and Physical Activity, 9-78. doi: 10.1186/14795868-9-78

Worthington, R., \& Whittaker, T. (2006). Scale development research. A content analysis and recommendations for best practices. The Counseling Psychologist, 34(6), 806-838. doi: 10.1177/0011000006288127

All content of Journal Motricidade is licensed under Creative Commons, except when otherwise specified and in content retrieved from other bibliographic sources. 